\title{
Intervening to change problematic alcohol use: using online personalized feedback to encourage changes in behaviour
}

\author{
Bridgette M Bewick
}

From International Network on Brief Interventions for Alcohol and Other Drugs (INEBRIA) Meeting 2013 Rome, Italy. 18-20 September 2013

This presentation outlines the development and evaluation of two online brief personalized feedback interventions for alcohol use (http://www.Unitcheck.co.uk and http://www.ChangeDrinking.com). By pulling together results from five individual studies, we aim to enable the audience to explore how the overall narrative enables additional insight in to our understanding of development, effectiveness, and implementation of online interventions. Methods and results from studies will be explained and contrasted. The theoretical underpinnings of the development of Unitcheck, an intervention initially developed for UK university students, will be explored briefly before outlining results of three randomised control trials. The results of a study employing qualitative thinkaloud methodology will then be presented. Evidence will be presented of the ability of Unitcheck to prompt users to actively engage with information presented, relating information to their own experience; resulting in an evaluation of their own drinking behaviour. Evidence will be presented of user's immediate cognitive and emotional reaction when comparing their own drinking with that of others. Next, we discuss how experiences with Unitcheck were applied to inform development of ChangeDrinking, an online screening and brief advice intervention for nonhelp-seeking individuals who have recently been hospital inpatients. The results of a study employing qualitative think-aloud methodology to understand how those identified as having substance misuse problems engage with ChangeDrinking will then be presented. The presentation will consider how context of implementation (e.g. university vs national hospital) shaped development of each intervention tool and subsequently impacted the evaluation

Correspondence: b.m.bewick@leeds.ac.uk

School of Medicine, Leeds Institute of Health Sciences, University of Leeds, UK

\section{Biomed Central

(c) 2013 Bewick; licensee BioMed Central Ltd. This is an Open Access article distributed under the terms of the Creative Commons Attribution License (http://creativecommons.org/licenses/by/2.0), which permits unrestricted use, distribution, and reproduction in any medium, provided the original work is properly cited. process. The synthesis of the results of the think-aloud studies with randomised control trial results enables insight in to potential mechanisms for behaviour change. This paper will consider the implication of results for our understanding of the use of online brief personalized feedback interventions for modifying alcohol use.

\section{Acknowledgements}

We acknowledge the financial support of the European Research Advisory Board (ERAB), Alcohol Education Research Council (AERC), NHS Leeds, NHS Kirklees, and the National Institute for Health Research (NIHR) under the Collaborations for Leadership in Applied Health Research and Care (CLAHRC) programme for Leeds, York and Bradford (LYBRA).

Published: 4 September 2013

doi:10.1186/1940-0640-8-S1-A11

Cite this article as: Bewick: Intervening to change problematic alcohol use: using online personalized feedback to encourage changes in behaviour. Addiction Science \& Clinical Practice 2013 8(Suppl 1):A11.

Submit your next manuscript to BioMed Central and take full advantage of:

- Convenient online submission

- Thorough peer review

- No space constraints or color figure charges

- Immediate publication on acceptance

- Inclusion in PubMed, CAS, Scopus and Google Scholar

- Research which is freely available for redistribution 